\title{
A teoria do valor de Marx e a educação do gosto
}

Marco Schneider

Doutorando em Comunicação (USP) e mestre em Comunicação e Cultura (UFRJ).

Professor da Unisuam e da FSMA.

E-mail: marco_schneider@ig.com.br

A mercadoria é, antes de mais nada, um objeto externo, uma coisa que, por suas propriedades, satisfaz necessidades humanas, seja qual for a natureza, a origem delas, provenham do estômago ou da fantasia ${ }^{1}$.

A função essencial da educação é, ou deveria ser, estimular o prazer do conhecimento. Por isso, toda educação constitui necessariamente uma educação do gosto, pois o gosto representa ao mesmo tempo expressão de sabor (prazer ou desprazer) e saber (conhecimento ou ignorância).

Sociedades divididas em classes, porém, fazem com que o acesso dos sujeitos aos objetos disponíveis de conhecimento e prazer se dê não só de forma socialmente desigual, mas também como uma experiência de níveis distintos, cindidos e até antagônicos da vida.

A tradição autoritária da educação formal nas sociedades contemporâneas, por sua vez, reproduz e reforça essa cisão no gosto em sabor e saber, opondo o último ao primeiro e idolatrando o conhecimento, preferencialmente em sua variante positiva ${ }^{2}$, instrumental, acrítica, além de desqualificar ou banir o prazer.

Já a indústria cultural completa o processo maniqueísta, opondo prazer a conhecimento de modo a idolatrar o primeiro, exclusivamente em suas manifestações mercadológicas, e a desqualificar o último - que só é valorizado, perifericamente, em sua forma instrumental de qualificação profissional, isto é, de subordinação do trabalho ao capital.

Temos então, no conjunto, além de uma apropriação socialmente desigual dos objetos degustáveis, a reprodução da cisão entre sabor e saber, e ainda uma desqualificação das formas de prazer desvinculadas do consumo, bem como das variantes não-instrumentais do conhecimento.

Desse processo, tentaremos identificar as causas, as conseqüências e algumas de suas manifestações, acreditando poder assim contribuir, ainda que modestamente, para sua superação.

A fim de evitar mal-entendidos, é importante frisar que não iremos aqui problematizar o gosto em termos de juízos estéticos, mas enquanto

1. MARX, Karl. O capital: crítica da economia política. São Paulo: Difel, 1982. Livro 1, v. 1, p. 41.

2. Cf. PARO, Victor Henrique. Administração escolar: introdução crítica. São Paulo: Cortez, 2001. 
3. Dictionnaire Philosophique (Dicionário Filosófico), verbete goût (gosto). Documento eletrônico: <http://www.voltaireintegral.com/Html/19/gout. $\mathrm{htm}>$. Acesso em: mar. 2006. Todas as citações de originais em língua estrangeira ao longo deste texto foram traduzidas por mim.

4. NIETZSCHE, apud AGAMBEN, Giorgio. Gosto. Enciclopédia Einaudi. Lisboa: Imprensa Nacional/Casa da Moeda, 1992 p. 139. (Criatividade-Visão, v. 25).

5. NIETZCHE, Friedrich. Le gai savoir (A Gaia Ciência). Paris: Gallimard, 1950. p. 271.

6. Id. Assim falou Zaratustra. Rio de Janeiro: Civilização Brasileira, 1986. p. 129.

7. BOURDIEU, Pierre. Distinction: a social critique of the judgement of taste (Distinção: uma crítica social do juízo de gosto). Cambridge, Massachussets: Harvard University Press, 2000. p. 77. expressão humana do valor de uso de tudo, ou seja, enquanto valoração sensível e intelectual, não-econômica, das experiências cognitivas e fruitivas em geral, às quais, aliás, o uso comum da palavra remete. Tampouco se trata de discutir critérios particulares de bom gosto, porém, precisamente, sua ausência em termos sociais; em outras palavras, o que discutiremos é o descritério autoritário da determinação econômica do conjunto das experiências cognitivas e fruitivas das pessoas, processo hegemonicamente mediado pela indústria cultural.

\section{O GOSTO: DO ESTÔMAGO À FANTASIA}

Voltaire certa vez observou que

O gosto, este sentido, este dom de discernir nossos alimentos, produziu em todas as línguas conhecidas a metáfora que exprime, pela palavra gosto, o sentimento das belezas e dos defeitos em todas as artes ${ }^{3}$.

Já o jovem Nietzsche, em seus estudos filológicos sobre os filósofos préplatônicos, demonstrou que o correspondente grego do termo gosto aproximava de um modo instigante as noções sabor e saber. A propósito da palavra grega sophos (sábio), ele escreveu:

Etimologicamente, pertence à família de sapio, degustar, sapiens, o degustante, saphes, perceptível ao gosto. Nós falamos de gosto na arte: para os gregos, a imagem do gosto é ainda mais alargada ${ }^{4}$.

Buscando, ao que tudo indica, atualizar essa imagem mais alargada, Nietzsche identifica no gosto, além da gênese da estética, a dos próprios juizos morais, nos "instintos, inclinações e repugnâncias" ${ }^{5}$. Ele chega mesmo a afirmar que

[...] a vida inteira é uma discussão de gostos e sabores! O gosto é, ao mesmo tempo, peso, balança e pesador; e ai de todo vivente que quisesse viver sem discutir de peso e balança e pesadores! ${ }^{6}$

Bourdieu diz algo parecido, abrindo um campo de estudos pouco explorado:

[...] uma aderência imediata, no nível mais profundo do habitus, aos gostos e desgostos, às simpatias e aversões, às fantasias e fobias é o que forja, mais do que opiniões declaradas, a unidade inconsciente de uma classe ${ }^{7}$.

Neste ponto surgem as seguintes questões: por que se tornou natural que se conceba sabor e saber, ou prazer e conhecimento, como níveis distintos e até antagônicos da experiência vital? Por que se deu essa cisão? De que forma a indústria cultural contribui para reproduzi-la na atualidade? Quais são as conseqüências sociais dessa reprodução?

Nossa hipótese inicial é que o desdobramento do termo gosto, em todas as linguas conhecidas, de um juízo estritamente gastronômico para cadeias significantes de outra ordem, deve-se ao fato de a satisfação da necessidade alimentar anteceder, necessariamente, todas as demais. Nos termos de Marx: 
[...] devemos lembrar um pressuposto de toda a existência humana e, portanto, de toda a história, a saber, que os homens devem estar em condições de poder viver a fim de "fazer história". Mas, para viver, é necessário antes de mais nada beber, comer, ter um teto onde se abrigar, vestir-se etc. O primeiro fato histórico é, pois, a produção dos meios que permitem satisfazer essas necessidades, a produção da própria vida material; trata-se de um fato histórico, de uma condição fundamental de toda a história, que é necessário, tanto hoje como há milhares de anos, executar dia a dia, hora a hora, a fim de manter os homens vivos ${ }^{8}$.

Assim, o primeiro saber humano é e só pode ter sido aquele orientado para a alimentação, que tem no paladar o sentido dos sabores, sua expressão sensível. Como não dispomos por natureza de força física ou velocidade superior às grandes feras, nem de asas, camuflagens epidérmicas, teias, venenos, garras, presas possantes etc., de um modo ou de outro desenvolvemos uma inteligência superior, que só pode ter surgido do esforço da espécie para, antes de mais nada, comer e não ser comida. E só a partir do momento em que a objetivação dessa inteligência, ou seja, a cooperação social e a tecnologia (da pedra, do fogo, da roda etc.), logrou transcender os limites naturais de todos os outros seres vivos, é que puderam surgir a consciência, a cultura, os valores, a história.

Tal objetivação é mediada pelo trabalho enquanto "atividade adequada a um fim”" Como este trabalho é necessariamente social, seu fim primordial também o é: assegurar a perpetuação da vida, na defesa coletiva contra as feras e contra a fome. Trata-se não somente de um fato histórico, mas do próprio nascimento da história: "Comerás o teu pão com o suor da tua face" (Gênesis 3,19).

Já a cisão do gosto em sabor e saber deve ter ocorrido a partir do momento em que se estabeleceu nas sociedades humanas a divisão do trabalho em braçal (inferior/sabor-labuta) e intelectual (superior/saber-governo), cuja representação no campo simbólico manifesta-se na divisão religiosa entre corpo (sede do pecado) e alma (sede da virtude), e na divisão platônica entre sentidos (percepção-distorção) e idéias (saber-verdade) ${ }^{10}$.

Se foi o catolicismo que assegurou, no Ocidente, ao longo dos séculos, a continuidade reificada da cisão, a racionalidade tecnocrática do capitalismo, derivada, conforme sustenta Weber ${ }^{11}$, da ética protestante, a radicaliza hoje em escala global, ao privilegiar, por meio da indústria cultural, seu porta-voz, muito sabor e pouco saber, na esfera do consumo e do tempo livre, e muito saber e pouco sabor, na esfera produtiva - sem falar do pouquíssimo saber e do imenso dissabor, na esfera do trabalho de baixa qualificação e na exclusão social.

Mas o homo sapiens, ao menos para estar à altura do nome que ele mesmo se atribui, deveria, ao mesmo tempo em que busca o saber, buscar o sabor, isto é, ser um homem degustante; só que não o é na medida de sua potência socialmente recalcada. Quando o é, tende a tornar-se menos sábio.

Isto não é fruto do acaso ou de alguma fantasmática natureza humana supra-histórica, mas da divisão demasiado histórica das sociedades em classes, com suas correspondentes mundivisões fetichistas (isto é, inconscientemente legitimadoras de ordens sociais calcadas na subordinação das pessoas às coisas
8. MARX, Karl; Friedrich, Engels. A ideologia alemã I. Lisboa: Editorial Presença, 1980. p. 32.

9. MARX, apud PARO, Victor Henrique. Administração escolar..., op. cit.

10. Cf. SCHNEIDER, Marco. Música e capital midiático: introdução a uma crítica da economia política do gosto. Rio de Janeiro: UFRJ, 2003. Dissertação de mestrado.

11. WEBER, Max. A ética protestante e o espírito do capitalismo. São Paulo: Livraria Pioneira Editora, 1967. 
12. Cf. DEBORD, Guy. A sociedade do espetáculo. Documento eletrônico: <http://www.geocities. com/jneves_2000/debord. $\mathrm{htm}>$. Acesso em: mar. 2006.

13. Cf. BAUDRILLARD, Jean. Pour une critique de l'économie politique do signe (Para uma crítica da economia política do signo). Paris: Gallimard, 1972.

14. Ibid., p. 97 ss.

15. MARX, Karl. Capítulo $\mathrm{VI}$ inédito de $\mathrm{O}$ capital: resultados do processo de produção imediata. São Paulo: Editora Moraes, 1985. p. 74.

16. Cf. ADORNO, Theodor W.; HORKHEIMER, Max. Dialética do esclarecimento. Rio de Janeiro: Jorge Zahar, 1985.
- hoje, à forma mercadoria, à lógica do capital; desenvolveremos este ponto a seguir), cuja versão contemporânea é o capitalismo turbinado global e sua sociedade do espetáculo ${ }^{12}$.

Cabe aqui lembrar uma crítica à noção de fetichismo desenvolvida por Baudrillard $^{13}$, que nos brinda com o postulado irônico de que fetichismo é uma categoria fetiche, questionando a validade do conceito, entre outros argumentos, com o recurso ao exemplo do pensamento mágico das tribos bantous, para quem a força difusa do mana é na verdade desviada para o proveito do "indivíduo ou do grupo"14; nesse caso, concordamos, não há fetichismo, que só ocorre, como nas sociedades contemporâneas, quando a força concreta do indivíduo ou do grupo é desviada para o proveito do mana, isto é, do capital (e de suas encarnações - dinheiro, mercadorias, títulos da dívida pública etc.) como um fim em si mesmo.

Assim, em termos rigorosos, a crítica não se sustenta, pois o conceito $f e$ tichismo não se refere a uma ilusão qualquer, mas a um fenômeno histórico e concreto, e à sua legitimação ideológica, na medida em que as relações entre as pessoas são subordinadas ao poder de uma relação social entre as coisas por elas produzidas, enquanto encarnações do capital em seu afã de se expandir continuamente, "como se tivesse dentro do corpo o amor"15.

Para tornar mais claro, é importante destacar que utilizamos o conceito fetiche sinteticamente, considerando o que há em comum entre as acepções psicanalítica e marxista, a saber, o fato de tratar-se, no fetichismo, de transferência de energia (libidinal ou força de trabalho) do sujeito para o objeto, carregando o último de valor (erótico, simbólico ou econômico) alienado do primeiro, na medida em que o sujeito só o é se sujeitado ao objeto.

\section{A INDÚSTRIA CULTURAL}

Se tomarmos a liberdade de estender o conceito de educação - entendida como a própria constituição do sujeito, em sua humanidade degustante, isto é, de sujeito do prazer e do conhecimento, através de sua inserção em uma determinada cultura - para além dos muros da escola, podemos afirmar que a indústria cultural vem ocupando cada vez mais um papel destacado nesse processo. Afinal, parece não haver dúvidas de que a cultura hegemônica das últimas décadas é a chamada cultura de massa.

O objetivo aqui, porém, não é analisar as especificidades dessa cultura, mas seu fundamento econômico totalitário, buscando atualizar a perspectiva crítica fundada por Adorno e Horkheimer na Dialética do esclarecimento ${ }^{16}$, em que foi cunhado o termo indústria cultural e onde se começou a problematizar as conseqüências sociais da mercantilização da cultura, sob um viés marxiano (mas não marxista, uma vez que os frankfurtianos deliberadamente se desvincularam de qualquer perspectiva de práxis revolucionária, por razões cuja exposição extrapola os limites deste artigo). 
Caso pareça contraditório o emprego alternado dos termos cultura de massa e indústria cultural, dado que Adorno e Horkheimer cunharam o último precisamente em oposição à noção de uma cultura de massa, que supostamente brotaria espontaneamente das massas, acredito que se possa escapar dessa armadilha entendendo a cultura de massa como uma expressão equivocada, mas útil, pois consagrada, para o conjunto da produção da indústria cultural.

Dito isso, a idéia-chave desta problemática está contida no conceito reificação, o qual, além de remeter à objetificação (coisificação) dos sujeitos, também diz respeito ao ato de representar e legitimar como natural, necessário (no sentido de inevitável), o que é histórico, passível de crítica e transformação mediante a práxis humana. O fundamento moderno da reificação (ou das formas modernas de reificação) é o fetichismo da mercadoria, expressão material do fetiche do valor, da subordinação da atividade humana ao imperativo cego de auto-expansão do capital.

Valor, em Marx, é a propriedade abstrata de uma mercadoria de ser equiparada com mercadorias distintas; é uma propriedade abstrata porque se distancia das propriedades concretas distintivas de cada mercadoria particular. É, em suma, a expressão daquilo que todas têm em comum: dispêndio de força de trabalho humana geral, ou de trabalho abstrato, fundamento de uma economia cuja produção é orientada para a troca de mercadorias (que tem como condição prévia a transformação da força de trabalho humana em mercadoria) como forma de valorizar crescentemente o valor, coisa que só é tecnicamente possível com a mediação do dinheiro.

Costuma-se confundir valor com valor de troca, e este com preço. São categorias diferentes. Valor de troca é a expressão quantitativa da magnitude do valor de uma mercadoria em relação a outra dela distinta. Essa magnitude independe das especificidades qualitativas e do tempo de trabalho concreto despendido na produção de cada produto particular, sendo determinada pela relação entre cada trabalho particular e o tempo de trabalho médio socialmente necessário, em um dado universo econômico (geográfico e histórico), para a sua produção. Já os preços são a expressão aproximada e flutuante dos valores de troca no mercado real ${ }^{17}$.

Adorno e Horkheimer, porém, apenas indicaram em linhas gerais os determinantes econômicos da mercantilização da cultura, detendo-se em suas conseqüências psicológicas e ideológicas, e em considerações filosóficas e estéticas. Mas o que nos interessa aqui é precisamente demonstrar em detalhe que a subsunção formal do trabalho de produção cultural ao capital (a subsunção real ainda não se efetivou plenamente) é o que determina, em última instância, a quantidade e a qualidade da produção cultural midiática, conseqüentemente o repertório cultural socializado e os gostos dos que são por ela educados.

A noção marxista de subsunção formal do trabalho ao capital refere-se ao processo histórico de alienação (no sentido jurídico de expropriação, que é o utilizado por Marx) do produtor dos meios de produção (instrumentos de trabalho - ferramentas e máquinas - e objetos de trabalho - matérias-primas)
17. Cf. MARX, Karl. O capital..., op. cit., e RUBIN, Isaak Illich. A teoria marxista do valor. São Paulo: Brasiliense, 1980. 
e da obra produzida, que ocorreu nos primórdios da revolução industrial, em função da divisão social (vertical, hierárquica) do trabalho, possibilitada pela acumulação primitiva de capital nas mãos da burguesia industrial emergente. Já subsunção real diz respeito à desqualificação das habilidades criativas do trabalhador como conseqüência da divisão técnica (horizontal) do trabalho. Buscando aplicar esses conceitos ao trabalho de produção cultural, iremos a seguir demonstrar que as conseqüências dessas subsunções no campo da produção cultural são profundas, tanto no que tange à forma e ao conteúdo da mercadoria cultural quanto na formação do gosto, na educação dos receptores tornados consumidores.

\section{A MÚSICA E O MÉTODO DIALÉTICO}

Antes de abordarmos diretamente a questão da subsunção formal da produção cultural ao capital, iremos esclarecer o porquê de termos escolhido a música como exemplo e o método que utilizaremos.

Quanto ao primeiro ponto, a música é a única forma de produção cultural pré-capitalista que foi, ao contrário da pintura, da dança, da escultura etc., convertida em produto industrial de massa, graças ao surgimento de tecnologias de registro, emissão e reprodução adequadas às suas propriedades materiais, bem como à sua produção e comercialização massivas.

Sobre o cinema e o design, o primeiro não é uma forma industrial de teatro, mas um produto mercantil e original desde o princípio; já o design, que pode ser entendido como a mercantilização da escultura ou do artesanato em geral, não exerce o mesmo papel educativo que o cinema ou a música: estes se tornaram, ao longo do século XX, algumas das principais referências identitárias, afetivas e lúdicas da esmagadora maioria das pessoas. Se a música o era antes, não podemos afirmar. Mas certamente não o era enquanto mercadoria massificada. Nem o teatro ou a escultura.

A literatura, por sua vez, não serve de exemplo, porque o mercado editorial não adquiriu dimensões similares e pela própria especificidade técnica do processo de produção de um livro: embora sua reprodução em série exija certa divisão do trabalho e maquinaria, o mesmo não ocorre com a produção da matriz, artesanal e individual. Já o filme e o disco (ou CD) demandam divisão do trabalho e maquinaria inclusive para a produção da matriz.

Quanto à TV, como o cinema, obviamente não existia antes da mercantilização da cultura, não constituindo, portanto, um objeto adequado para nossa análise.

A música, assim, junto ao cinema, é a arte de massa por excelência. Mas o fato de ter havido música antes de ela ter-se tornado mercadoria, oferecenos um parâmetro de comparação que nos permite pensar a especificidade do modo capitalista de socializar cultura em relação a formas anteriores, coisa que o cinema não faz. Ao mesmo tempo, essa perspectiva metodológica favorece o reconhecimento do caráter histórico geral da forma atual de socialização da cultura, o que ajuda a pensar sua superação. 
Nosso objeto é, portanto, a subordinação do gosto (em sua acepção dilatada, que é a do uso comum, sem que as pessoas tenham consciência disso) à economia; nosso objetivo, demonstrar a estupidez destrutiva de uma tal subordinação, que reproduz a velha e reificada cisão entre prazer e conhecimento, bem como esboçar um arcabouço teórico que ajude a pensar sua superação prática; nosso método, uma análise histórica panorâmica das transformações contraditórias da indústria fonográfica, como ilustração das tendências gerais da mercantilização da cultura, efetuada sob uma perspectiva dialética, isto é, que utilize como instrumental conceptual as noções de aparência (o povo gosta da produção midiática), fenômeno (o povo não tem muito acesso a outras fontes de educação) e essência (a indústria cultural exerce uma dupla função nas sociedades contemporâneas, uma econômica e outra ideológica, sendo ao mesmo tempo instância de acumulação de capital e de reificação do gosto); totalidade (a história da indústria fonográfica) e níveis de totalização (o nível econômico dessa história); quantidade (a escala operacional crescente) e qualidade (a legitimação global de valores simbólicos ou juízos de gosto midiáticos); classes sociais (o monopólio da emissão por parte da classe dominante, seja ela a burguesia, sejam estratos burocráticos); infra (produção material) e superestrutura (produção e reprodução ideológica); alienação (no sentido de expropriação material); fetiche (o totalitarismo da valorização do valor como fim em si); determinação em última instância da economia, em sentido ontológico (modo de os homens produzirem suas condições de vida e a si mesmos, em cooperação ou conflito com os outros homens) e histórico (modo de produção específico e transitório); superação dialética (aufheben, suspender, negar, conservar, superar).

\section{A SUBSUNÇÃO FORMAL DA PRODUÇÃO MUSICAL AO CAPITAL}

Com o advento do comércio de partituras (existente desde o séc. XVI ${ }^{18}$, mas extremamente intensificado no séc. XIX $\left.{ }^{19}\right)$, ocorre algo inédito na história da música: pela primeira vez o produto (a música propriamente dita) é separável do ato de produção (aqui entendida como execução), ainda que indiretamente; com os primeiros registros fonográficos, o processo se completa, tornando-se o produto diretamente separável do ato de produção.

A partir de então, sua produção e socialização passam a depender de outros meios além da voz humana e de instrumentos musicais, demandando equipamentos cada vez mais sofisticados - e caros - de gravação (microfones, gravadores etc.), instalações adequadas (estúdios) etc.

Seu consumo, igualmente, separa-se pela primeira vez do ato de produção, requerendo mais do que a presença física de produtor e consumidor no mesmo espaço e ao mesmo tempo, ou seja, requerendo equipamentos de irradiação, captação e reprodução de sons.

O conjunto desses equipamentos, que viabilizam a produção e o consumo em escala social, não pertence, porém, aos produtores, mas a empresas capita-
18. Cf. JOURDAIN, Robert. Música, cérebro e êxtase. Rio de Janeiro: Objetiva, 1998. p. 124.

19. Cf. ELIAS, Norbert. Mozart: sociologia de um gênio. Rio de Janeiro: Jorge Zahar, 1995. 
20. Cf. GUEIROS JR., Nehemias. Direito autoral no show business. Rio de Janeiro: Gryphus, 1999.

21. Cf. SCHNEIDER, Marco, op. cit.

22. Lobão, nome artístico de João Luiz Woerdenbag Filho (Rio de Janeiro, 11 de outubro de 1957), é cantor de rock e pop brasileiro. Em 1999, rompeu com as gravadoras e o lançamento de seu disco A Vida é Doce foi realizado num esquema inédito, com distribuição pela internet, bancas de jornais e lojas de departamento. [N.E.]

23. Cf. LÉVY, Pierre. Cibercultura. Rio de Janeiro: Ed. 34, 1999. listas cada vez mais gigantescas, que atualmente operam em escala global. Isto implica uma racionalização crescente do processo produtivo, que nada tem a ver com o valor objetivo, estético, do produto, mas com seu valor econômico.

Embora a concepção e a execução da produção musical não possam ser totalmente alienadas do produtor (nos referimos aqui a seus conhecimentos musicais e habilidade técnica), elas são em grande parte, sobretudo no planejamento (concepção) do que será ou não produzido, na determinação do tempo e dos recursos a serem empregados no processo produtivo e, em certa medida, na definição de determinadas características formais do produto - o qual, aliás, é propriedade da gravadora, restando aos compositores e músicos as migalhas (em alguns casos volumosas) de direitos autorais e conexos ${ }^{20}$.

Assim, se a subsunção real (técnica) do produtor ao capital é somente parcial, a subsunção formal torna-se gradualmente total ${ }^{21}$.

Por outro lado, as gravadoras, ultimamente, tendem a não mais possuir estúdios, limitando-se a financiar a serialização do produto e administrar sua comercialização; os estúdios, porém, não passaram a ser patrimônio dos produtores, mas de outros capitalistas. Nos casos em que pertencem ao músico, este se torna um capitalista, parte terceirizada da cadeia produtiva, na medida em que aluga seu estúdio para outros músicos. Se não alugá-lo, utilizando-o somente como parte dos meios de produção para sua própria produção musical - o que está longe de constituir a regra -, nem por isso deixa de estar subordinado à indústria cultural como um todo para poder trocar seu produto por dinheiro de modo a não ter prejuízo - a única maneira de poder socializar sua produção sem falir.

No geral, os músicos não dispõem de estúdios e, quando podem, arcam com o custo da produção e tentam vender o produto à gravadora. Se conseguirem (o que não ocorre na maioria das vezes), irão tornar-se uma espécie de sócio minoritário na empreitada comercial; se não conseguirem, terão de cavar brechas nos muros das empresas de irradiação e distribuição do produto, ou seja, concorrem com a gravadora, que dispõe de recursos e logística incomparavelmente superiores. Ainda que haja exceções à regra, como a experiência recente de Lobão ${ }^{22}$ ilustra, estas não apontam para a sua superação, que só é realisticamente concebível para além do capital.

Quanto às novas tecnologias, que para alguns sugerem uma alternativa ou mesmo uma solução diante dessas tendências ${ }^{23}$, permanecem em um plano totalmente marginal em relação à produção e difusão massivas: de nada adiante o produtor dispor de um software de gravação se não possui os meios de difusão; difundir algo, individualmente, pela internet, por enquanto, é como jogar no oceano uma garrafa com uma carta dentro. E já existem gigantescas empresas que capitalizam essas garrafas, papéis de carta e oceanos virtuais.

É verdade que novas alternativas de divulgação on-line vêm sendo desenvolvidas, através de blogs, links com sites onde se pode adquirir música gratuitamente em formato MP3 etc. Isto parece promissor, pois, tornando-se conhecido por esses meios, o músico passa a conquistar um público consumidor potencial para 
seus shows e CDs, independente da grande mídia. Até segunda ordem, porém, a difusão da música em escala efetivamente massiva ainda passa pelo circuito das indústrias culturais.

Cumpre, portanto, socializar todo o aparato tecnológico e logístico disponível em uma lógica operacional super-humana, não calcada na valorização do valor, mas na superação concreta e universal da cisão entre prazer e conhecimento, que é a base biopolítica (ou seja, referente à constituição dos sujeitos concretos em meio às tensas relações de poder vigentes, cuja expressão mais profunda é a luta de classes) do desgosto nodal da época.

\section{POR UMA EDUCAÇÃO DO GOSTO PARA ALÉM DA VÁLORIZAÇÃO DO VALOR}

A produção musical foi puxada das nuvens macias da superestrutura simbólica para a terra dura da estrutura econômica, que passa a determinar sua qualidade e sua quantidade, de acordo com sua propriedade de valorizar valor. Como dizia Marx,

O volume das massas de mercadorias produzidas pela produção capitalista é estabelecido pela escala dessa produção e pelo imperativo de expansão contínua dela, e não por uma órbita predeterminada da oferta e da procura, das necessidades a satisfazer ${ }^{24}$.

Conseqüentemente, a educação do gosto musical em escala social é igualmente determinada por esse imperativo. $\mathrm{O}$ mesmo vale para a totalidade da produção midiática. Mas isto não elimina o papel desempenhado por esses produtos em nível superestrutural, isto é, enquanto valores simbólicos ou juízos de valor gustativos: sua função conservadora, aí, é reificar afetos e mundivisões adequados (ou inofensivos) aos imperativos econômicos e políticos hegemônicos.

A única explicação plausível para a existência de vozes discordantes na indústria cultural é ser ela, como as demais instâncias sociais, atravessada pela luta de classes, expressão maior do conjunto de antagonismos e contradições característicos do modo de produção capitalista: se um discurso ideologicamente discordante é eficiente midiaticamente enquanto suporte da valorização do valor, ele passa, até segunda ordem. Além disso, não é possível submeter integralmente à produção musical (e cultural, em um sentido mais amplo) a lógica do capital, reproduzindo continuamente cinco bilhões de cópias de uma mesma canção. Como cantava Bob Marley, parafraseando Abrahan Lincoln, "you can fool some people sometime, but you can not fool all the people all the time" (você pode enganar algumas pessoas por algum tempo, mas não pode enganar todas as pessoas para sempre).

Por mais maleáveis e estandardizáveis que os gostos sejam, as pessoas não são formigas. Mas para que possam realizar plenamente sua humanidade, é necessário que o conjunto de suas práxis cognoscentes e fruitivas seja dilatado e enriquecido; para tanto, é fundamental que se dê uma desmercantilização

24. MARX, Karl. O capital: crítica da economia política. Rio de Janeiro: Civilização Brasileira, 2003. Livro 2, p. 86. 
da produção cultural, por conseqüência, da educação gustativa hegemônica de massa. Para isso acontecer, os meios de produção e irradiação de cultura teriam de operar dentro de uma lógica exclusivamente humana, isto é, cultural, desconectando-se do imperativo da valorização do valor. Esta lógica pressupõe, retomando Gramsci ${ }^{25}$, que todo ser humano é intelectual, portanto produtor de cultura, embora não exerça predominantemente esta função social devido à divisão técnica e hierárquica do trabalho em sociedades cindidas em classes antagônicas. Porém, para fazer história, como vimos, é preciso que se esteja vivo.

É claro que nem todos serão músicos (ou cineastas etc.), mas muito mais músicos poderão ser ouvidos, bem como muito mais vozes, em sentido amplo, o que pressupõe também uma superação do modelo comunicacional calcado em um número exíguo de emissores falando para bilhões de receptores.

A internet, enquanto instrumento, sugere a possibilidade prática de se efetuar tal superação. Contudo, para ser operacionalizada nesse sentido, muito resta a ser feito.

Talvez essa luta deva iniciar-se precisamente na escola. Aliás, o foco do debate dos que lidam diretamente com a questão da democratização da comunicação tem-se deslocado da luta pelo fim da propriedade privada dos meios de produção e irradiação de mensagens (a indústria cultural clássica) para a pauta da inclusão digital. Por que não ambas as coisas, sobretudo diante das novas perspectivas de convergência tecnológica?

Resumo: O objetivo deste trabalho é propor uma crítica ao caráter não-democrático da indústria cultural e da educação formal em geral, à luz da teoria do valor de Marx, de modo a identificar certa operacionalidade complementar de ambas as instâncias na perpetuação da cisão entre prazer e conhecimento, que a noção de gosto carrega. $O$ fio condutor dessa reflexão, que tem por objeto a subordinação do gosto à economia, começa com uma análise da cisão na própria etimologia do termo gosto; em seguida, uma breve história da mercantilização da música deverá ilustrar a forma como tal subordinação tem ocorrido. A escolha da música como exemplo devese ao fato de se tratar do único objeto de prazer e conhecimento massificado pela indústria cultural que já existia antes de sua emergência, o que nos fornece uma boa referência para a compreensão do processo histórico mais amplo da subordinação do gosto às leis de ferro do valor.

Palavras-chave: gosto, dialética, música.
Abstract: This paper aims to propose a critical approach, based on Marx value's theory, about the non-democratic nature of cultural industry and general formal education, identifying both as two faces of a single perpetuating process of rupture between pleasure and knowledge, rupture that can be found in the concept of taste. This approach, which subject is the subordination of taste to economy, begins from an analysis of the quoted rupture within the etymology of the word taste; following this analysis, a brief history of the process by which music gradually becomes a commodity might illustrate how the subordination occurred. Music is the example here because it is the only mass culture subject of pleasure and knowledge that already existed before the emergence of a cultural industry, so a good reference to understand the wider historic process of the subordination of taste to value's iron rules.

Keywords: taste, dialectic, music. nio. Os intelectuais e organização da cultura. São Paulo: Círculo do Livro, 1982. 